\title{
Evaluating Beijing's human carrying capacity from the perspective of water resource constraints
}

\author{
Yingxuan Zhang ${ }^{1}$, Min Chen ${ }^{2}$, Wenhua Zhou ${ }^{1}$, Changwei Zhuang ${ }^{1}$, Zhiyun Ouyang ${ }^{1, *}$ \\ 1. Research Center for Eco-Environmental Sciences, Chinese Academy of Sciences, Beijing 100085, China. E-mail: zyx2008y@yahoo.cn \\ 2. University of Illinois at Urbana-Champaign, Urbana, 61801, USA
}

Received 11 July 2009; revised 02 December 2009; accepted 27 December 2009

\begin{abstract}
As the demands on limited water resources intensify, concerns are being raised about the human carrying capacity of these resources. However, few researchers have studied the carrying capacity of regional water resources. Beijing, the second-largest city in China, faces a critical water shortage that will limit the city's future development. We developed a method to quantify the carrying capacity of Beijing's water resources by considering water-use structures based on the proportions of water used for agricultural, industrial, and domestic purposes. We defined a reference structure as 45:22:33 (\% of total, respectively), an optimized structure as 40:20:40, and an ideal structure as 50:15:35. We also considered four domestic water quotas: $55,75,95$, and $115 \mathrm{~m}^{3} /($ person·yr). The urban carrying capacity of 10-12 million was closest to Beijing's actual 2003 population for all three water-use structures with urban domestic water use of $75 \mathrm{~m}^{3}$ /(person·yr). However, after accounting for our underlying assumptions, the adjusted carrying capacity is closer to 5-6 million. Thus, Beijing's population in 2003 was almost twice the adjusted carrying capacity. Based on this result, we discussed the ecological and environmental problems created by Beijing's excessive population and propose measures to mitigate these problems.
\end{abstract}

Key words: urban population carrying capacity; regional water resources; sustainable urban development; water resource management DOI: $10.1016 / \mathrm{S} 1001-0742(09) 60253-9$

\section{Introduction}

The concept of carrying capacity is rooted in demography, biology, and applied ecology (Clarke, 2002). In ecology, carrying capacity is defined as the maximum population of a species that a habitat can support without permanently impairing the habitat's productivity (Rees, 1997). Concerns over human carrying capacity can be traced back to Malthus' portrayal of human population growth restrained by available food supplies (Seidl and Tisdell, 1999), but modern studies mainly focus on the population that can be sustained by regional, national, and global agricultural potential productivity (Cao et al., 1995; Harris and Kennedy, 1999; Hopfenberg, 2003; Yue et al., 2008). Models have been developed to estimate Earth's carrying capacity (Cohen, 1995; Marchetti et al., 1996; Meyer and Ausubel, 1999), but there is little agreement about the most appropriate model.

Human carrying capacity is an indicator of regional sustainability (Yount, 1998), and achieving regional sustainability is important because social institutions and ecological functioning are closely linked at this scale (Graymore et al., 2009). Studies of a regional ecosystem's urban population carrying capacity emphasize the need to manage demand rather than supply, since the supply is

\footnotetext{
* Corresponding author. E-mail: zyouyang@ @rcees.ac.cn
}

usually limited to some degree. The regional ecosystem is often represented using units such as river basins, letting researchers analyze the ecosystem's structure, functions, and processes within those boundaries and determine the carrying capacity of the regional resources and environment. The concept of a sustainable carrying capacity defined by the regional ecosystem's characteristics is based on two premises. First, it must be possible to sustain the regional ecosystem's normal operation; as a result, researchers must calculate the quantity of resources and environmental capacity required to sustain these functions. Second, it is necessary to evaluate the urban population and intensity of urban activities that the natural resources can support after meeting the need of ecosystem. This approach prioritizes the health of the regional ecosystem and potentially avoids defects related to overcomplicated calculations because of the more limited scope of the analysis.

A region's carrying capacity will change over time due to changes in the available resources and in the environment, and can only be calculated by specifying the time period and the natural and socioeconomic development levels during that period. Because excessive demand in one region should not be solved by exporting problems to another region (i.e., by overexploiting another region's resources), trade with other regions should be limited to 
sustainable levels; to maintain a reasonable carrying capacity, relatively high self-sufficiency must be maintained, and water resources in particular should not rely on interbasin exchanges. It is also necessary to protect the living standards of urban residents, which are constrained by existing regional resources and environmental conditions and by current technological, cultural, economic, and policy conditions. To simplify the calculations, major constraints must be grouped; typical groups include land, water, and energy.

The carrying capacity depends strongly on water resources. However, researchers disagree about how to define this carrying capacity is inconsistent. There have also been few theoretical studies of carrying capacity based on regional water resources because this capacity is most often included within a larger theory of sustainable development (UNCSD, 1996). For example, Falkenmark and Lundqvist (1998) used estimates of the maximum global use of water resources to study how carrying capacity is determined by regional water resources. Another example is a study of the Florida Keys Basin's carrying capacity in the United States (NRC, 2002), in which researchers modeled carrying capacity under different land-use scenarios.

In China, severe environmental problems have forced the government to initiate a series of studies to determine the carrying capacity based on regional water resources in areas with a severe water shortage, such as western China and the North China Plain (Xia and Zhu, 2002; Zhu et al., 2009). These studies mainly focused on the scale of social and economic development that can be sustainably supported by a particular basin's or region's water resources without disturbing the ecosystem's normal operation (Zhang and Guo, 2006).

In China, a city's population is determined by the urban population growth rate and the economic development goals. Constraints imposed by the available water and other natural resources are rarely considered in these plans, which may explain why most Chinese cities are facing severe water shortages and experiencing ecological problems in surrounding areas. Beijing, capital and second-largest city in China, also faces a critical water shortage (Jiao, 2007; RSPRG and BMCDR, 2001). In the present study, we developed a method of quantifying Beijing's carrying capacity based on the available water resources by assessing the available resources, evaluating the environmental water requirements, and analyzing water consumption by urban and rural residents. Based on the analysis, we discussed how to resolve some of the problems created by the imbalance between demand for water and the available supply.

\section{Study area}

Beijing Municipality covers an area of $16,400 \mathrm{~km}^{2}$ in the northern part of the North China Plain, between $39^{\circ} 26^{\prime} \mathrm{N}$ and $41^{\circ} 03^{\prime} \mathrm{N}$ and between $115^{\circ} 25^{\prime} \mathrm{E}$ and $117^{\circ} 30^{\prime} \mathrm{E}$. Beijing is characterized by alluvial plains in the south and east, and by hills and mountains in the north, northwest, and west. Beijing has an East Asian monsoon climate with four distinct seasons, characterized by hot and humid summers and by cold, windy, and dry winters. Beijing has an average annual temperature of $12.5^{\circ} \mathrm{C}$, an average annual precipitation of $566 \mathrm{~mm}$ with large annual fluctuations, and an average annual evaporation of $1842 \mathrm{~mm}$ (BMBS, 19812006).

Beijing is China's political, cultural, and international communication center. As a result of China's rapid social and economic development, Beijing has experienced dramatic urbanization. From 1978 to 2005, Beijing's registered population increased from 8.497 to 11.807 million, and the actual population increased from 8.715 to 15.380 million, including immigrants from other areas. The urban population increased from 4.790 to 12.861 million during this period, accounting for $55.0 \%$ and $83.6 \%$ of the municipality's total population, respectively (BMBS, 1981-2006). The built-up area has also increased substantially, from $366 \mathrm{~km}^{2}$ in 1984 to $1182 \mathrm{~km}^{2}$ in 2005 (CNBS, 1985-2006).

Beijing is located in the Haihe River Basin, which includes five drainage systems: the Jiyunhe Canal, Chaobaihe River, Beiyunhe Canal, Yongdinghe River, and Daqinghe River. Beijing's drinking water is mainly obtained from the catchments of the Yongdinghe and Chaobaihe rivers, which pass through a mountainous area north of Beijing. The total area of these catchments is about $50,000 \mathrm{~km}^{2}$, but most of this area lies beyond Beijing's administrative boundaries.

Currently, the per capita annual water resource is less than $300 \mathrm{~m}^{3}$, which is only $12.5 \%$ of the national average and $3.3 \%$ of the world average. Beijing experienced droughts from 1999 to 2007, and since September 2003, Beijing has been forced to transfer emergency water from surrounding provinces such as Hebei and Shanxi annually to provide enough water for the city's normal operations. Eventually, Beijing may be forced to transfer water from the Yangtze River Basin, which is thousands of miles away, because inadequate water resources are limiting its social and economic expansion (Jiao, 2007).

\section{Methods}

\subsection{Overall framework}

Evaluating the carrying capacity permitted by the available water resource involves many disciplines, including hydrology, ecology, environmental sciences, economics, management, sociology, and law. Many methods can be used, of which the most common are trend analysis, fuzzy comprehensive evaluation, principle-components analysis, system dynamics, multiobjective decision-making and analysis, and the projection pursuit approach (Feng et al., 2006; Zhang and Guo, 2006). However, from a management perspective, scenario analysis is most appropriate because it reveals the effects of different management policies on the carrying capacity. This approach involves studying the urban socioeconomic system, natural ecosystems, and their interactions. Given the fuzzy dynamic 
nature of the relationships among humans, other organisms, and their physical natural environment, it is difficult to use either simple or complex mathematical models to describe these relationships. In this study, we identified and analyzed the major factors that affect the use of Beijing's water resources using a combination of qualitative and quantitative methods. We then developed water-use scenarios (consumption structures for agricultural, industrial, and domestic use) based on the corresponding water demand, and calculated the carrying capacity based on the currently available water resources.

Because of changes in irrigation methods, the economic structure of agriculture, and the planting structure, as well as the free trade in agricultural and related products, it is difficult to determine Beijing's agricultural water quota. As a result, it becomes difficult to evaluate the effect of this component of overall water use on the carrying capacity. To overcome this difficulty, we controlled the total agricultural water consumption. In addition, the composition of water use for industrial purposes is complex because the measurement standards differ among company sizes, product types, technologies, and production processes. Consequently, it is also difficult to determine the industrial water quota (Zhang, 2003). For this reason, we also controlled the total volume of water for industrial consumption. Using these assumptions, Beijing's carrying capacity can be determined based on the total water available for urban domestic use and the related service industries, and the comprehensive per capita urban domestic water use, which includes water use by urban households and urban public water use.

$P_{\mathrm{U}}=W_{\mathrm{U}} / A_{\mathrm{U}}=\left[\left(W_{\mathrm{T}}-W_{\mathrm{E}}\right) \alpha-W_{\mathrm{R}}\right] / A_{\mathrm{U}}$

where, $P_{\mathrm{U}}$ (person) is the urban population carrying capacity based on the available water resource; $W_{\mathrm{U}}\left(\mathrm{m}^{3}\right)$ is the total water available for urban domestic water use; $A_{\mathrm{U}}\left(\mathrm{m}^{3} /(\right.$ person $\left.\cdot \mathrm{yr})\right)$ is the comprehensive per capita urban domestic water quota; $W_{\mathrm{T}}\left(\mathrm{m}^{3}\right)$ is the total available water resource; $W_{\mathrm{E}}\left(\mathrm{m}^{3}\right)$ is the minimum eco-environmental water demand; $\alpha(\%)$ is the percentage of domestic water use; and $W_{\mathrm{R}}\left(\mathrm{m}^{3}\right)$ is the total water available for rural domestic water use.

Currently the average domestic water quota is 120$140 \mathrm{~L} /$ (person-day) in the city's near suburbs and 80-100 $\mathrm{L} /$ (person-day) in the city's remote suburbs (BWSO and BWSMC, 2003). In contrast, BMBS (1981-2006) reported that the comprehensive urban domestic water quota averaged $260 \mathrm{~L} /($ person-day) in urban areas. Therefore, we chose 2:1 for the ratio of the comprehensive urban domestic water quota to the annual rural domestic water quota, which is consistent with the data of Ruan and Wei (2004). Beijing's urban population was about $75 \%$ of the total (BMBS, 1981-2006), therefore, the rural population is one-third of the urban population. Based on these assumptions:

$W_{\mathrm{R}}=P_{\mathrm{R}} A_{\mathrm{R}}=\left(P_{\mathrm{U}} / 3\right)\left(A_{\mathrm{U}} / 2\right)=P_{\mathrm{U}} A_{\mathrm{U}} / 6$

where, $P_{\mathrm{R}}$ is the rural population carrying capacity based on the currently available water resource, and $A_{\mathrm{R}}$ is the comprehensive per capita rural domestic water quota.

Plugging Eq. (2) into Eq. (1) to obtain Eq. (3):

$P_{\mathrm{U}}=6\left(W_{\mathrm{T}}-W_{\mathrm{E}}\right) \alpha / 7 A_{\mathrm{U}}$

from Eq. (3), it is obvious that we require data on four parameters to determine the carrying capacity based on current water resource availability.

\subsection{Evaluation of Beijing's total available water re- sources}

The data used to calculate the total available water resource $\left(W_{\mathrm{T}}\right)$ was obtained from the Beijing Water Resource Bulletin from 1986 to 2002 (BWA, 1986-2005). Because of the droughts that occurred after 1999, the Beijing Water Authority arranged many emergency water transfers from the Yunzhou Reservoir in Hebei Province and the Cetian Reservoir in Shanxi Province. Since 2003, many water-conservation measures have been implemented, and wastewater reclamation and reuse have increased. As a result, the water resource data collected before 2003 are not consistent with those collected after 2003. Therefore, we have used the available water resource data before 2003 to evaluate the carrying capacity; subsequent data are provided solely for reference purposes.

\subsection{Evaluation of the minimum eco-environmental wa- ter demand}

Since different amounts of water are needed to maintain the ecosystem at different quality levels, we initially evaluated three levels of eco-environmental water demand (Zuo et al., 2002): at the maximum level, vegetation grows well, resulting in a vigorous ecosystem; at the reasonable level, vegetation grows acceptably but the ecosystem is less vigorous than in the maximum scenario; at the minimum level, vegetation grows poorly and the ecosystem's integrity is poor but acceptable. Based on the health of Beijing's regional ecosystem, the intense conflicts over the available water, and the high water demand, we chose the minimum eco-environmental water demand scenario in the remainder of our study. This means that the water consumed by the region's natural vegetation is mainly provided by precipitation and groundwater, not by Beijing's available water resources. Therefore, we only need to consider the water required to compensate for the excessive extraction of groundwater, to provide the base flow requirements for the rivers, and to permit water use in the urban environment.

\subsection{Allocation of water use among agricultural, indus- trial, and domestic uses}

The percentage of domestic water use $(\alpha)$ was based on scenarios for the allocation of water among Beijing's agricultural, industrial, and domestic uses. Liu et al. (2003) reported that agricultural water use has decreased during the past 20 years. During this period, industrial water use initially increased, then decreased, and has recently stabilized, whereas domestic water use has increased. Since Beijing has experienced many adjustments of its industrial 
structure and has implemented many water-conservation measures during the past 20 years, it is difficult to propose a better water-use structure for the current water-use pattern or to further improve current water-use techniques.

By considering Beijing's current condition, we designed three scenarios for water allocation among agricultural, industrial, and domestic uses. The first scenario used the water allocation pattern in 2002 as the reference structure. The second scenario considers the water allocation pattern in 2005 as an optimized structure that reflects the current water use and assumes that the maximum adjustments of water use have been achieved. The third scenario is the ideal structure for Beijing, which might be possible if more advanced water use techniques are developed or the city's economic structure adjusts to use water more sustainably.

\subsection{Comprehensive per capita urban domestic water quotas}

Water quotas serve as comprehensive indicators of the results of local policies, regulations, water prices, living standards, technologies, public awareness of water conservation, and management levels. Whether or not these quotas are determined scientifically and rationally, they play an important role in calculating the carrying capacity.

We therefore considered Beijing's natural and socioeconomic conditions and those of its surrounding areas, and used the water quotas from similar foreign cities as a reference (RSPRG and BMCDR, 2001). Based on previous research and statistical information related to water quotas (BMBS, 1981-2006; Feng et al., 2003; RSPRG and BMCDR, 2001; Ruan and Wei, 2004), we defined four levels of comprehensive per capita urban domestic water quotas: $55,75,95$, and $115 \mathrm{~m}^{3} /$ (person·yr).

\section{Results and discussion}

Unless otherwise noted, all water resource values reported in this section represent annual totals.

\subsection{Calculation of Beijing's total available water re-} sources $\left(W_{\mathbf{T}}\right)$

Table 1 provides the basic statistical information on Beijing's water resources from 1986 to 2005. Based on those data, the available water resources from 1986 to 2002 (excluding 1987, for which no data were available) averaged $39.5 \times 10^{8} \mathrm{~m}^{3}$. This number is close to the results of Ruan and Wei (2004) and Liu et al. (2003), which were $37.7 \times 10^{8}$ and $39.9 \times 10^{8} \mathrm{~m}^{3}$, respectively. We therefore used this mean value as the current available water resources in the rest of our analysis.

Table 1 shows that precipitation varies greatly between years, resulting in large inter-annual changes in the total available water. When precipitation decreases greatly, the ways to balance the water demand and supply are excessive extraction of groundwater and emergency water transfers from outside Beijing; the former practice has resulted in a continuous decline in the groundwater table in the plains around Beijing. At the end of 2002, the average depth to groundwater was $17.32 \mathrm{~m}$, which was $10.08 \mathrm{~m}$ deeper than that at the end of 1980 (BWA, 1986-2005).

\subsection{Calculation of minimum eco-environmental water demand in Beijing $\left(W_{\mathbf{E}}\right)$}

\subsubsection{Water used to complement excessive extraction of groundwater}

The excessive extraction of groundwater is a serious problem. If this trend continues, it may lead to disasters such as land subsidence and ruptures of the ground surface, and will increase the risk of groundwater dewatering. Thus, planners must strictly control the extraction of groundwater, and must find ways to replenish this resource, such as using rain to recharge groundwater during flood periods. The artificial recharge of groundwater accounts for different percentages of the total groundwater exploited around the world, with values ranging from $12 \%$ in Britain to $30 \%$ in West Germany (BHRI et al., 2004). In the present

Table 1 Basic statistical information on Beijing's water resources from 1986 to 2005

\begin{tabular}{|c|c|c|c|c|c|c|c|c|}
\hline \multirow[t]{2}{*}{ Year } & \multicolumn{8}{|c|}{ Water quantity $\left(\times 10^{8} \mathrm{~m}^{3}\right)$} \\
\hline & Precipitation & $\begin{array}{r}\text { Surface } \\
\text { water }\end{array}$ & Groundwater & $\begin{array}{c}\text { Water calculated } \\
\text { repeatedly }\end{array}$ & $\begin{array}{r}\text { Water produced } \\
\text { in Beijing }\end{array}$ & $\begin{array}{l}\text { Water flows } \\
\text { into Beijing }\end{array}$ & $\begin{array}{r}\text { Available } \\
\text { water }\end{array}$ & $\begin{array}{r}\text { Water flows out } \\
\text { of Beijing }\end{array}$ \\
\hline 1986 & 94.1 & 14.20 & 17.91 & 5.08 & 27.03 & 10.70 & 37.73 & 10.28 \\
\hline 1988 & 99.3 & 24.65 & 21.21 & 6.68 & 39.18 & 16.15 & 55.33 & 19.92 \\
\hline 1989 & 80.6 & 12.00 & 13.98 & 4.43 & 21.55 & 6.33 & 27.88 & 8.73 \\
\hline 1990 & 112.1 & 19.02 & 23.71 & 5.87 & 36.86 & 11.73 & 48.59 & 14.60 \\
\hline 1991 & 110.0 & 24.17 & 23.68 & 5.56 & 42.29 & 12.84 & 55.13 & 15.94 \\
\hline 1992 & 82.5 & 10.90 & 15.18 & 3.64 & 22.44 & 10.27 & 32.71 & 11.61 \\
\hline 1993 & 71.1 & 8.28 & 14.92 & 3.53 & 19.67 & 6.57 & 26.24 & 9.03 \\
\hline 1994 & 121.6 & 25.76 & 36.58 & 16.92 & 45.42 & 13.95 & 59.37 & 24.48 \\
\hline 1995 & 100.1 & 15.56 & 28.93 & 14.15 & 30.34 & 17.28 & 47.62 & 21.62 \\
\hline 1996 & 110.2 & 25.95 & 30.26 & 10.34 & 45.87 & 25.12 & 70.99 & 39.41 \\
\hline 1997 & 68.9 & 10.61 & 16.40 & 4.76 & 22.25 & 8.50 & 30.75 & 19.44 \\
\hline 1998 & 115.3 & 17.83 & 29.21 & 9.34 & 37.70 & 14.45 & 52.15 & 21.43 \\
\hline 1999 & 62.7 & 5.16 & 12.81 & 3.75 & 14.22 & 5.79 & 20.01 & 10.73 \\
\hline 2000 & 73.6 & 6.34 & 15.18 & 4.66 & 16.86 & 7.11 & 23.97 & 10.24 \\
\hline 2001 & 77.6 & 7.78 & 15.70 & 4.28 & 19.20 & 5.29 & 24.49 & 7.35 \\
\hline 2002 & 69.4 & 5.25 & 14.69 & 3.83 & 16.11 & 2.60 & 18.71 & 6.24 \\
\hline 2003 & 76.1 & 6.06 & 14.79 & 2.45 & 18.40 & 4.18 & 22.58 & 7.91 \\
\hline 2004 & 90.6 & 8.16 & 16.54 & 3.35 & 21.35 & 6.32 & 27.67 & 9.14 \\
\hline 2005 & 78.8 & 7.58 & 18.46 & 2.86 & 23.18 & 4.59 & 27.77 & 8.48 \\
\hline
\end{tabular}


study, we chose a value of $20 \%$ based on Beijing's actual water resource conditions. The average total groundwater exploited in Beijing during the study period was $25.0 \times 10^{8}$ $\mathrm{m}^{3}$ (BWA, 1986-2005). Therefore, $5.0 \times 10^{8} \mathrm{~m}^{3}$ of water should be used to counteract the excessive extraction of groundwater.

\subsubsection{River base flow}

Chen et al. (2002) calculated Beijing's ecoenvironmental water demand for nearly the same period as in our study. They found that Beijing's current total eco-environmental water demand was $39.8 \times 10^{8} \mathrm{~m}^{3}$ for six primary water uses: forest vegetation in mountain areas, water and soil conservation, afforestation in plains areas, river base flows, and river sediment discharge. Since we have chosen the minimum eco-environmental water standard in our study, we will only consider the basic eco-environmental water demand of rivers, which includes the base flow and sediment discharge. Chen et al. (2002) used the multi-year average runoff in the month with the minimum river flow to represent the volume of river water that must be maintained to protect river ecosystems, which averaged $7.1 \times 10^{8} \mathrm{~m}^{3}$. They also calculated the water required for river sediment discharge $\left(5.5 \times 10^{8}\right.$ $\mathrm{m}^{3}$ ) during the flood period. In our study, we assumed that artificial measures (e.g., dredging) can be taken to remove river sediments, and that the water required for river sediment discharge can thus be set to zero. Therefore, the basic eco-environmental water demand of rivers was $7.1 \times 10^{8} \mathrm{~m}^{3}$.

\subsubsection{Urban environmental water demand}

Chen et al. (2002) also calculated Beijing's urban environmental water demand, in which the water used for urban greening was $1.2 \times 10^{8} \mathrm{~m}^{3}$. However, they did not account for water used to dilute and purify polluted water. Beijing's average sewage treatment rate is as high as $80 \%$, with 9 sewage treatment plants in urban areas and
14 plants in suburban areas. We assumed that these plants would dilute and purify all the polluted water produced in Beijing and that no additional water must be consumed for this purpose. In addition, we assumed that recycled water would be used to replenish rivers and lakes in the parks downstream of Beijing and to irrigate vegetation in Beijing's parks and gardens. Therefore, we set the urban environmental water demand to zero, and did not consider the cumulative effects of previous water pollution or the delayed effects of measures to control water pollution.

\subsection{Calculation of Beijing's percentage of domestic wa- ter use $(\alpha)$}

Table 2 shows the amounts and proportions of water used for Beijing's agricultural, industrial, and domestic uses (BWA, 1986-2005). In 2002, the ratio was about 45:22:33 (percentage of total water available, respectively), versus about 40:20:40 in 2005. We used the proportions in 2002 as the reference water-use structure, and the proportions in 2005 as the optimized structure.

Liu et al. (2003) and Liu and Kang (2007) have shown that Beijing's agricultural water demand will continue to decrease. Beijing can maximize its gross domestic product by adjusting its industrial structure to decrease the proportion of agriculture, and demand for agricultural and related products can be satisfied by importing these products. However, a more comprehensive analysis must consider four points. First, agriculture has distinctive properties and characteristics; it requires large amounts of water, generally accounting for up to $70 \%$ of the total regional water use. Second, agriculture provides both food and ecological services. Third, Beijing's degraded ecological environment requires that water saved from agriculture be used to replenish the eco-environmental water instead of making it available for industrial and domestic purposes. Only by doing so will it become possible to mitigate the conflict between urban sprawl and the city's inadequate

Table 2 Beijing's water-use structure from 1986 to $2005^{*}$

\begin{tabular}{|c|c|c|c|c|c|c|c|}
\hline \multirow[t]{2}{*}{ Year } & \multirow{2}{*}{$\begin{array}{l}\text { Total water available } \\
\text { Water quantity } \\
\left(\times 10^{8} \mathrm{~m}^{3}\right)\end{array}$} & \multicolumn{2}{|c|}{ Agricultural water } & \multicolumn{2}{|c|}{ Industrial water } & \multicolumn{2}{|c|}{ Domestic water } \\
\hline & & $\begin{array}{l}\text { Water quantity } \\
\left(\times 10^{8} \mathrm{~m}^{3}\right)\end{array}$ & $\begin{array}{l}\text { Proportion } \\
\text { of total }(\%)\end{array}$ & $\begin{array}{l}\text { Water quantity } \\
\left(\times 10^{8} \mathrm{~m}^{3}\right)\end{array}$ & $\begin{array}{l}\text { Proportion } \\
\text { of total }(\%)\end{array}$ & $\begin{array}{l}\text { Water quantity } \\
\left(\times 10^{8} \mathrm{~m}^{3}\right)\end{array}$ & $\begin{array}{l}\text { Proportion } \\
\text { of total (\%) }\end{array}$ \\
\hline 1986 & 36.55 & 19.46 & 53.2 & 9.91 & 27.1 & 7.18 & 19.6 \\
\hline 1988 & 36.65 & 20.82 & 56.8 & 9.43 & 25.7 & 6.40 & 17.5 \\
\hline 1989 & 37.66 & 22.02 & 58.5 & 9.19 & 24.4 & 6.45 & 17.1 \\
\hline 1990 & 35.66 & 20.23 & 56.7 & 8.39 & 23.5 & 7.04 & 19.8 \\
\hline 1991 & 37.16 & 21.52 & 57.9 & 8.21 & 22.1 & 7.43 & 20.0 \\
\hline 1992 & 41.40 & 19.08 & 46.1 & 11.34 & 27.4 & 10.98 & 26.5 \\
\hline 1993 & 41.79 & 19.75 & 47.3 & 12.45 & 29.8 & 9.59 & 22.9 \\
\hline 1994 & 42.61 & 20.36 & 47.8 & 11.88 & 27.9 & 10.37 & 24.3 \\
\hline 1995 & 41.78 & 18.77 & 44.9 & 11.24 & 26.9 & 11.77 & 28.2 \\
\hline 1996 & 40.94 & 18.95 & 46.3 & 11.76 & 28.7 & 9.30 & 22.7 \\
\hline 1997 & 40.26 & 18.12 & 45.0 & 11.0 & 27.3 & 10.07 & 25.0 \\
\hline 1998 & 40.47 & 17.39 & 43.0 & 10.84 & 26.8 & 10.83 & 26.8 \\
\hline 1999 & 41.71 & 18.45 & 44.2 & 10.56 & 25.3 & 12.70 & 30.5 \\
\hline 2000 & 40.40 & 16.49 & 40.8 & 10.52 & 26.0 & 12.96 & 32.1 \\
\hline 2001 & 38.93 & 17.40 & 44.6 & 9.18 & 23.6 & 12.05 & 31.0 \\
\hline 2002 & 34.62 & 15.45 & 44.6 & 7.54 & 21.8 & 10.83 & 31.3 \\
\hline 2003 & 35.80 & 13.80 & 38.5 & 8.40 & 23.5 & 13.00 & 36.3 \\
\hline 2004 & 34.55 & 13.50 & 39.1 & 7.66 & 22.2 & 12.78 & 37.0 \\
\hline 2005 & 34.50 & 13.22 & 38.0 & 6.80 & 20.0 & 13.38 & 39.0 \\
\hline
\end{tabular}

* Domestic water use excludes urban environmental water, therefore, the percentages of agricultural, industrial, and domestic water may not total $100 \%$. 
water supply. Finally, even though agricultural and related products can be imported from other regions, we must remain aware of the problems with this approach. For example, it is difficult to ensure the safety and freshness of imported products. The transportation costs of these products will also increase. In addition, importing these products could lead to an inefficient use of large areas of local farmland. Based on these considerations, we set the minimum proportion of agricultural water use to $40 \%$, and set the ideal proportion to $50 \%$.

After the founding of the People's Republic of China in 1949, the new government planned to turn Beijing into China's most important industrial base and to convert Beijing from "Consuming City" into "Producing City". This strategy conflicted with Beijing's characteristics as a political, historical, and cultural city, and weakened and inhibited the development of nearby Tianjin City. More seriously, the emphasis on heavy industry with high consumption of resources and heavy generation of pollution was inappropriate for the region's natural resources and eco-environment, and ignored the risk of severe water shortages. Although Beijing has continuously adjusted its industrial structure and implemented watersaving technologies since 1980, sharp conflicts have arisen between urban development and the limited water supply. The large-scale urban expansion during the study period further exacerbated water shortages. Based on historical and current urban development patterns and on Beijing's special nature as a political and cultural center, we propose that the city's proportion of industrial water use should not exceed $20 \%$, and that the ideal proportion should be $15 \%$.

Since the ideal proportions of agricultural and industrial water uses were set at $50 \%$ and $15 \%$, respectively, the ideal proportion of domestic water use should be $35 \%$. Therefore, the ideal water-use structure in Beijing should be a ratio of $50: 15: 35$.

\subsection{Calculation of Beijing's comprehensive per capita urban domestic water quotas $\left(A_{\mathbf{U}}\right)$}

The Planning Report on South-to-North Water Diversion of Beijing defined Beijing's average comprehensive urban domestic water quota as $266 \mathrm{~L} /($ person-day) in 2005 , versus $289 \mathrm{~L}$ in 2010 . The Sustainable Water Use Planning of Capital City for Early 21st century (2001-2005) defined an average domestic water quota of $337 \mathrm{~L} /($ person-day) in 2005, versus $360 \mathrm{~L}$ in 2010 (RSPRG and BMCDR, 2001).

However, Beijing's population has kept increasing, and these water quotas have become difficult to achieve. BMBS (1981-2006) reported that the comprehensive per capita urban domestic water quota increased from 141 $\mathrm{L} /$ (person·day) in 1980 to $260 \mathrm{~L} /$ (person-day) in 2000 (no data are available after 2000). Beijing experienced droughts from 1999 to 2007, therefore, many waterconservation measures were implemented, leading to a continuous decrease in the average domestic water consumption.

Although the number of immigrants has continued to increase, Beijing's total domestic water consumption has actually decreased. That is, the $260 \mathrm{~L} /($ person-day) (equivalent to $95 \mathrm{~m}^{3} /($ person·yr)) appears to represent the maximum domestic water use since 2000. In addition, Ruan and Wei (2004) and Feng et al. (2003) suggested that the average urban comprehensive domestic water use in Tianjin City in 2000 was $208 \mathrm{~L} /$ (person-day) (equivalent to $75 \mathrm{~m}^{3} /($ person $\cdot y r)$ ). This number is probably similar to Beijing's consumption because Tianjin's natural and socioeconomic conditions are similar. Since Tianjin is less developed than Beijing, its average urban domestic water use is probably lower than that of Beijing. However, Tianjin's consumption level can be used as a model for Beijing because Beijing currently faces a severe water shortage that will require ongoing reductions in domestic consumption. On this basis, Beijing's average urban domestic water use for the past 10 years ranged from 75 to $95 \mathrm{~m}^{3}$.

We established two additional domestic water-use scenarios to support our analysis. First, major innovations such as gradually replacing flush toilets with composting toilets could reduce domestic water use by $25 \%$ to $33 \%$, thereby decreasing the average per capita urban domestic water use to around $55 \mathrm{~m}^{3} /($ person $\cdot y r)$, which is close to Beijing's average rural domestic water use. Second, we accounted for Beijing's special status and needs as China's capital by considering a luxurious domestic water use level of $115 \mathrm{~m}^{3} /$ (person·yr).

\subsection{Estimation of carrying capacity based on Beijing's water resources}

Thus far, we have calculated the four parameters $\left(W_{\mathrm{T}}\right.$, $W_{\mathrm{E}}, \alpha$, and $\left.A_{\mathrm{U}}\right)$ required to estimate Beijing's carrying capacity based on the available water resources. In this section, we will discuss the range of values for these parameters and the consequences for carrying capacity.

From 1986 to 2002, the annual available water resources averaged $39.5 \times 10^{8} \mathrm{~m}^{3}$. We have therefore used this number as the current total available water resource. We defined the basic eco-environmental water demand of rivers to be $7.1 \times 10^{8} \mathrm{~m}^{3}$ and the water needed to compensate for the excessive extraction of groundwater to be $5.0 \times 10^{8} \mathrm{~m}^{3}$. Adding these values provides a minimum eco-environmental water demand of $12.1 \times 10^{8}$ $\mathrm{m}^{3}$. Beijing's reference water-use structure is $45: 22: 33$, versus an optimized water-use structure of 40:20:40 and an ideal water-use structure of 50:15:35. We then defined the comprehensive urban domestic water use for four different consumption scenarios: 55, 75, 95, and $115 \mathrm{~m}^{3} /($ person $\cdot y r)$. Table 3 summarizes the results.

We calculated Beijing's carrying capacity based on the available water resources using Eq. (3) and the scenario combinations in Table 3. As the proportion of domestic water use increases and the comprehensive per capita urban domestic water use decreases, the carrying capacity increases. With a comprehensive urban domestic water use of $75 \mathrm{~m}^{3}$ /(person.yr), the carrying capacity is closest to Beijing's current population for all three water-use structures. However, this does not mean that the carrying capacity equals the current urban population of 10-12 million, because our calculations sacrifice certain economic 
Table 3 Beijing's urban population carrying capacity under four domestic water-use scenarios and three water-use structures based on the available water resource

\begin{tabular}{lllc}
\hline Water-use structure & \multicolumn{2}{c}{ Carrying capacity $\left(\times 10^{4}\right.$ persons $)$} \\
\cline { 2 - 4 } & $55 \mathrm{~m}^{3} /($ person·yr $)$ & $75 \mathrm{~m}^{3} /($ person $\cdot \mathrm{yr})$ & $95 \mathrm{~m}^{3} /(\mathrm{person} \cdot \mathrm{yr})$ \\
\hline Reference $(45: 22: 33, \alpha=0.33)$ & 1409.1 & 1033.4 & 815.8 \\
Optimized $(40: 20: 40, \alpha=0.40)$ & 1708.1 & 1252.6 & 988.9 \\
Ideal $(50: 15: 35, \alpha=0.35)$ & 1494.5 & 1096.0 & 865.3 \\
\hline
\end{tabular}

Water-use structures represent the ratio of agricultural to industrial to domestic water consumption (\% of total).

and eco-environmental benefits for Beijing and the surrounding provinces. In particular, we have not accounted for six factors.

First, the total available water used in our calculation comes from a catchment area of $50,000 \mathrm{~km}^{2}$, which extends far beyond Beijing's administrative boundaries (Jiao, 2007; Li, 2005). Without the water imported from outside Beijing, the carrying capacity would decrease greatly.

Second, we have not considered "virtual" water (which enters Beijing in imported agricultural and related products), and this represents another way to divert water from outside Beijing. The water diverted into Beijing in this way increased from $32.5 \times 10^{8} \mathrm{~m}^{3}$ in 2004 to $54.5 \times 10^{8} \mathrm{~m}^{3}$ in 2007, after a peak at $60.4 \times 10^{8} \mathrm{~m}^{3}$ in 2003 (Liu and Kang, 2007).

Third, water in the Guanting reservoir will inevitably be polluted by cities along the upper reaches of the Yongdinghe River. The water flowing out of Beijing would then further pollute bodies of water that supply cities along the lower reaches of the Yongdinghe and Chaobaihe River, as well as the water in the Bohai Sea. It will be technically difficult and very expensive to control this pollution, and it will take a long time to achieve this control (He et al., 2005; Sun et al., 2002).

Fourth, we based our analysis on the minimum ecoenvironmental water demand, which will cause ecoenvironmental problems. The region's groundwater has been severely overexploited for decades, leading to a risk of permanent depletion of the groundwater supply. Some rivers have dried up for long periods and some rivers have become severely polluted as a result of inadequate ecological flows. Where vegetation is growing poorly, it cannot conserve soils and water effectively, and thus ecosystem health decreases (Chen et al., 2002).

Fifth, rainfall in the Haihe River Basin exhibits significant variation during and between years. All the region's rivers have synchronous changes in runoff and commonly experience periods with continuously low water. The longest period of low water was 20 years. Under natural conditions, the whole region is vulnerable to drought, and its ecosystems lack sufficient self-regulation and selfadjustment capacity (Ruan and Wei, 2004).

Sixth, there is limited room to reduce industrial water consumption and comprehensive urban domestic water consumption because of the difficulty of achieving significant technological breakthroughs, the high cost of replacing old equipment with new equipment, and the long time required for such replacement (Liu et al., 2003).

If we assign a weight of 0.5 to the volume of available water to account for the effects of these six factors,
Beijing's carrying capacity would decrease to half of the values shown in Table 3.

\section{Conclusions and suggestions}

Based on our analysis and a scenario with a comprehensive urban domestic water use of $75 \mathrm{~m}^{3} /$ (person.yr), Beijing's urban carrying capacity based on the currently available water resource is 5-6 million people. If we assume an urbanization level of $75 \%$, then the region's total carrying capacity would be between 6.88 and 8 million people. By 2003, Beijing's total population was already 14.56 million, including an urban population of 11.51 million (BMBS, 1981-2006). It is obvious that the actual population size already exceeds the carrying capacity by a factor of nearly 2. This is a fundamental source of the region's severe water shortages. Beijing's current urban expansion and intensification of human activities are occurring at the price of potentially severe ecological damage, and possibly at the expense of surrounding provinces. To increase the sustainability of Beijing's economic and living conditions, the city's development strategy must be adjusted as soon as possible.

The goal of calculating the carrying capacity based on the available regional water resources is to permit the development of an effective and feasible water-management plan. In other words, by estimating the maximum possible population size permitted by the available regional water resources, we can determine how urban development must proceed to maintain the population below the maximum limit defined by this carrying capacity. This kind of planning is rarely done because planners focus too heavily on urban development and construction while ignoring the resource and environmental constraints. As a result, the actual population often exceeds the sustainable population. Beijing provides a good example of this problem.

Given the current situation, the population size should be determined based on the available regional water resources, and this should serve as the basis for future development and environmental policies. This does not mean that we must reduce the current city size. Rather, we must find ways to prevent further urban expansion by developing powerful policy tools that provide alternatives. One practical way to accomplish this would be to reduce the intensity of production and living activities in the city, with a focus on reducing the consumption of water resources. Although Beijing's planners have encouraged water conservation and improved water-use efficiency, there is considerable need for improvement, and researchers must be encouraged to find new or improved, 
more efficient, and rapidly implementable technological solutions that can be implemented quickly. Further adjustments of Beijing's economic structure will be required, with the goal of relocating industries with high consumption of water resources to areas where the available water resource can sustain these activities. All of these measures should be carefully investigated and evaluated in light of a new way of thinking in which the demand for water is based on the water supply, rather than using water demand to determine the required water supply. In a nutshell, we must begin to balance society's demands with the environment's ability to meet those demands, and if necessary, must find ways to decrease those demands until sustainable urban development becomes possible.

\section{Acknowledgments}

This work was supported by the Knowledge Innovation Project of the Chinese Academy of Sciences (No. KZCX2YW-422).

\section{References}

BHRI, BUCEA, BUT, BDG (Beijing Hydraulic Research Institute, Beijing University of Civil Engineering and Architecture, Beijing University of Technology, Beijing Drainage Group), 2004. Planning Studies on Early Rainwater Pollution and Control in Beijing.

BMBS (Beijing Municipal Bureau of Statistics), 1981-2006. Beijing Statistical Yearbook 1981-2006. China Statistics Press, Beijing.

BWA (Beijing Water Authority), 1986-2005. Beijing Water Resource Bulletin.

BWSO, BWSMC (Beijing Water Saving Office, Beijing Water Saving Management Center), 2003. Prediction of Water Demand for Primary Industry and Rural Domestic Use.

Cao M K, Ma S J, Han C R, 1995. Potential productivity and human carrying capacity of an agro-ecosystem: an analysis of food production potential of China. Agricultural Systems, 47: 387414.

Chen L H, Yu X X, Wang L X, 2002. Calculation of ecological water use in Beijing City. Journal of Soil and Water Conservation, 16(4): 116-118.

CNBS (China National Bureau of Statistics), 1985-2006. China City Statistical Yearbook 1985-2006. China Statistics Press, Beijing.

Clarke A L, 2002. Assessing the carrying capacity of the Florida Keys. Population and Environment, 23(4): 405-418.

Cohen J E, 1995. Population growth and the Earth's human carrying capacity. Science, 269: 341-346.

Falkenmark M, Lundqvist J, 1998. Towards water security: Political determination and human adaptation crucial. Natural Resources Forum, 21(1): 37-51.

Feng S Y, Chen S J, Huo Z L, Li W C, 2006. Review on the present situation and future prospect of water resources carrying capacity in China. Journal of East China Institute of Technology, 29(4): 301-306.

Feng Y L, Han W X, Wang H J, Lian J J, Huang J M, 2003. Study on the region water resources carrying capacity. Advances in Water Science, 14(1): 109-113.

Graymore M L M, Sipe N G, Rickson R E, 2009. Sustaining human carrying capacity: A tool for regional sustainability assessment. Ecological Economics, 69(3): 459-468.

Harris J M, Kennedy S, 1999. Carrying capacity in agriculture: global and regional issues. Ecological Economics, 29: 443-461.

He G P, Zhou D, Yang Z S, Zhao H Y, Li C J, 2005. Current status and evaluation of groundwater resources exploitation in the plain area of Beijing. Hydrogeology $\mathcal{E}$ Engineering Geology, 2: 45-48.

Hopfenberg R, 2003. Human carrying capacity is determined by food availability. Population and Environment, 25(2): 109-117.

Jiao Z Z, 2007. Facing water shortage and construction of the circulating water affairs. China Water, 8: 30-31.

Li W, 2005. Preliminary discussion on the mechanism of long-term protection and compensation of water resources in Beijing and Zhangjiakou City. Hebei Water Resources, 8: 43-44.

Liu B, Kang S Z, 2007. Studies on virtual water impact to water resources bearing capacity of Beijing Municipality. China Water Resources, 8: 8-11.

Liu B Q, Yao Z J, Gao Y C, 2003. Trend and driving forces of water consumed structure changes in Beijing. Resources Science, 25(2): 38-43.

Marchetti C, Meyer P S, Ausubel J H, 1996. Human population dynamics revisited with the logistic model: how much can be modeled and predicted? Technological Forecasting and Social Change, 52(1): 1-30.

Meyer P S, Ausubel J H, 1999. Carrying capacity: a model with logistically varying limits. Technological Forecasting and Social Change, 61(3): 209-214.

NRC (National Research Council), 2002. A Review of The Florida Keys Carrying Capacity Study. National Academy Press, Washington DC.

Rees W E, 1997. Urban ecosystems: the human dimension. Urban Ecosystems, 1: 63-75.

RSPRG, BMCDR (Rational Scale of Population Research Group, Beijing Municipal Commission of Development and Reform), 2001. Research on Rational Scale of Population in Beijing.

Ruan B Q, Wei C J, 2004. Establishment of Water Resources Security System in The Capital City Area. Science Press, Beijing.

Seidl I, Tisdell C, 1999. Carrying capacity reconsidered: from Malthus' population theory of cultural carrying capacity. Ecological Economics, 31: 395-408.

Sun C Z, Gao Y A, Hu X T, Zhang G Y, Zhang J K, 2002. Analyses of ground settling in the eastern suburbs of Beijing. Geotechnical Engineering World, 5(11): 27-29.

UNCSD (United Nations Commission on Sustainable Development), 1996. Indicators of Sustainable Development: Framework and Methodologies. United Nations, New York.

Xia J, Zhu Y Z, 2002. The measurement of water resources security: a study and challenge on water resources carrying capacity. Journal of Nature Resource, 17(3): 263-269.

Yue T X, Tian Y Z, Liu J Y, Fan Z M, 2008. Surface modeling of human carrying capacity of terrestrial ecosystems in China. Ecological Modelling, 214: 168-180.

Yount J D, 1998. Human carrying capacity as an indicator of regional sustainability. Environmental Monitoring and Assessment, 51: 507-509.

Zhang B C, Guo F, 2006. Reviews on the research of water resources carrying capacity. Shanghai Economic Review, 10: 39-43.

Zhang S F, 2003. Some suggestions to industrial water use management in Beijing. Beijing Water Resources, 4: 10-12.

Zhu Y H, Drake S, Lü H, Xia J, 2009. Analysis of temporal and spatial differences in eco-environmental carrying capacity related to water in the Haihe River basins, China. Water Resource Management, 24(6):1089-1105.

Zuo Q T, Zhou K F, Yang L, 2002. Study on the quantity of water resources and the ecological water use in water resources programming. Arid Land Geography, 25(4): 296-301. 